\title{
Newly Designed Graphene Cellular Monolith Functionalized with Hollow Pt-M (M = Ni, Co) Nanoparticles as the Electrocatalyst for Oxygen Reduction Reaction
}

Yazhou Zhou, ${ }^{\mathrm{a}, \mathrm{b}}$ Juan Yang, ${ }^{\text {a }}$ Chengzhou Zhu, ${ }^{\mathrm{b}}$ Dan Du, ${ }^{\mathrm{b}}$ Xiaonong Cheng, ${ }^{\mathrm{a}}$ Clive Hsu Yen, ${ }^{\mathrm{c}}$ Chien M Wai, ${ }^{\mathrm{c}}$ and Yuehe Lin $^{* \mathrm{~b}}$

${ }^{\mathrm{a}}$ School of Materials Science and Engineering, Jiangsu University, Zhenjiang, 212013, Jiangsu, PR China.

${ }^{\mathrm{b}}$ School of Mechanical and Materials Engineering, Washington State University, Pullman, WA 99164-2920, United States.

${ }^{c}$ Department of Chemistry, University of Idaho, Moscow, Idaho 83844-2343, United States

*E-mail: yangjuan6347@,mail.ujs.edu.cn; yuehe.lin@,wsu.edu 


\section{Electrochemical Measurements:}

Catalyst preparation for electrochemical measurements: The electrolyte used was $70 \%$ redistilled $\mathrm{HClO}_{4}$, diluted to $0.1 \mathrm{M}$ concentration. The working electrodes were prepared by applying catalyst ink onto the republished GC disk electrodes. ${ }^{1}$ In brief, the as-prepared catalyst was dispersed in isopropanol (99.5\%), Nafion (5\%), water (V/V/V: 2/0.05/8) and ultrasonicated to form a uniform catalyst ink $\left(2 \mathrm{mg} \mathrm{mL}^{-1}\right) . \mathrm{A}$ total of $10 \mu \mathrm{L}$ of dispersed catalyst ink was applied onto the pre-polished GC disk electrode. The target catalyst loading on the GC disk electrodes are, $3.0 \mu \mathrm{g}_{\mathrm{Pt}}$ for $\mathrm{Pt}-\mathrm{Ni} / \mathrm{GCM}$ and $4 \mu \mathrm{g}_{\mathrm{Pt}}$ for commercial Pt/C (20 wt $\left.\%\right)$. The well-prepared electrodes were dried at $60{ }^{\circ} \mathrm{C}$ for $30 \mathrm{~min}$ before the electrochemical tests. In addition, all the samples are uniformly dispersed on the GC disk electrodes and the coverage is almost the same.

The electrochemical surface area (ECSA) of each catalyst was determined using the mean integral charge of the hydrogen adsorption/desorption areas in $\mathrm{CV}^{2}$ :

$E C S A=\frac{Q_{H}}{0.21 \times[P t]}$

Where $\mathrm{Q}_{\mathrm{H}}(\mathrm{mC})$ is the charge due to the hydrogen adsorption/desorption in the hydrogen region $(0.05-0.3 \mathrm{~V})$ of the $\mathrm{CVs}, 0.21 \mathrm{mC} \mathrm{cm}^{-2}$ is the electrical charge associated with monolayer adsorption of hydrogen on $\mathrm{Pt}$, and $[\mathrm{Pt}]$ is the loading of $\mathrm{Pt}$ on the working electrode.

The kinetic current was calculated from the polarization curve using the well-known mass-transport correction according to the Levich-Koutecky equation ${ }^{3}$ : $1 / i=1 / i_{k}+1 / i_{d}$

Where $i$ is the experimentally obtained current, $i_{\mathrm{k}}$ refers to the mass-transport free kinetic current, and $i_{\mathrm{d}}$ the measured diffusion-limited current. The mass activity of the catalysts can be determined via calculation of $i_{\mathrm{k}}$ and normalization to the Pt-loading ${ }^{4}$. From the same experimental data, one can also calculate the specific activity of different catalysts via determination of $i_{\mathrm{k}}$ and normalization with the ECSA.

Accelerated durability test (ADT) for catalysts: The catalysts were first pretreated using 200 cycles $\mathrm{CV}$ scans by potential sweeping from 0.05 to $1.0 \mathrm{~V}$ (vs. RHE) at a 
scan rate of $100 \mathrm{mV} \mathrm{s}^{-1}$ in $\mathrm{N}_{2}$-saturated $0.1 \mathrm{M} \mathrm{HClO}_{4}$ solution at the room temperature. Thereafter, the durability of the catalysts is studied by an ADT in $\mathrm{O}_{2}$-saturated $0.1 \mathrm{M}$ $\mathrm{HClO}_{4}$ solution at a room temperature by cycling the potential between 0.6 and $1.0 \mathrm{~V}$ for duration of 20,000 potential cycles at sweep rates of $200 \mathrm{mV} \mathrm{s}^{-1}$. The CVs before and after ADT were recorded at a scan rate of $50 \mathrm{mV} \mathrm{s}^{-1}$ in $\mathrm{N}_{2}$-saturated $0.1 \mathrm{M} \mathrm{HClO}_{4}$ solution. The ECSA of catalysts before and after ADT were calculated from CVs as aforementioned method. And then, ORR polarization curves of the catalysts before and after ADT were also conducted at room temperature in $\mathrm{O}_{2}$-saturated $0.1 \mathrm{M} \mathrm{HClO}_{4}$ with a sweep rate of $10 \mathrm{mV} \mathrm{s}^{-1}$ and a rotation speed of $1600 \mathrm{rpm}$. The changes of mass activity and specific activity of catalysts after ADT were calculated through method mentioned above.

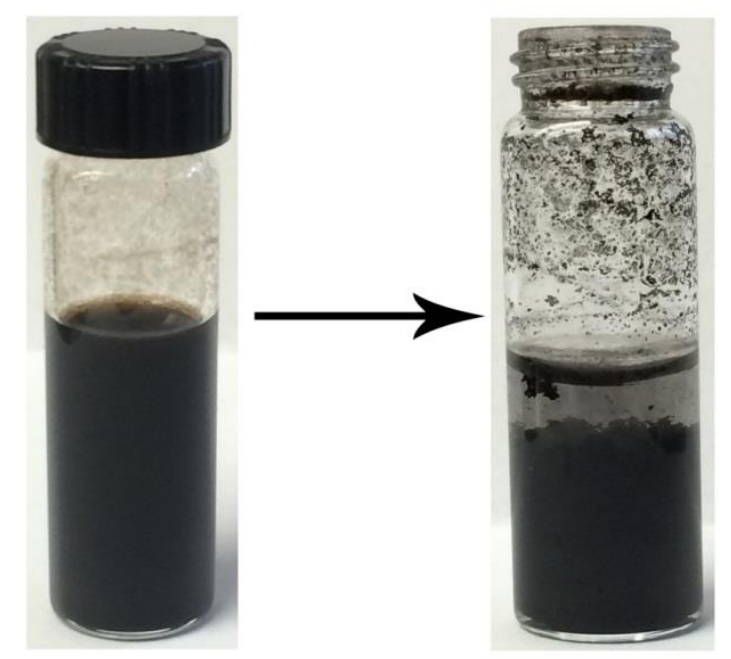

Figure S1. The Photos of Sample Prepared using the $20 \mathrm{mg} \mathrm{NaBH}_{4}$, and the Monolith Cannot be Obtained. 


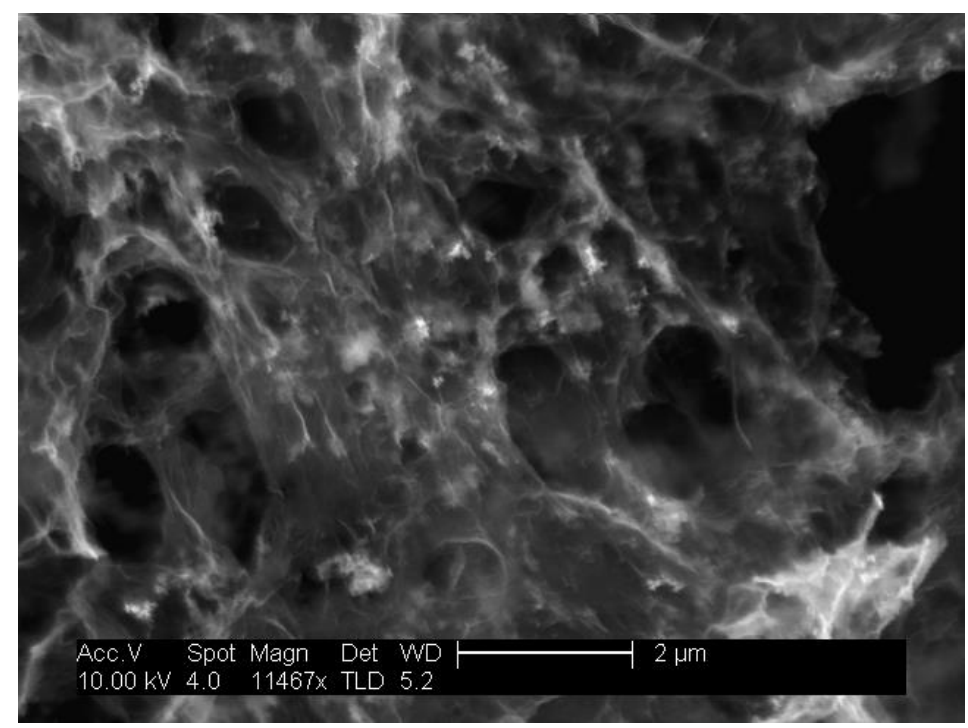

Figure S2. The TEM Image of Pt-Ni/GCM Prepared through AA Reduction of $\mathrm{Pt}^{2+} / \mathrm{GO}$ Precursors and without Sonochemical Process.

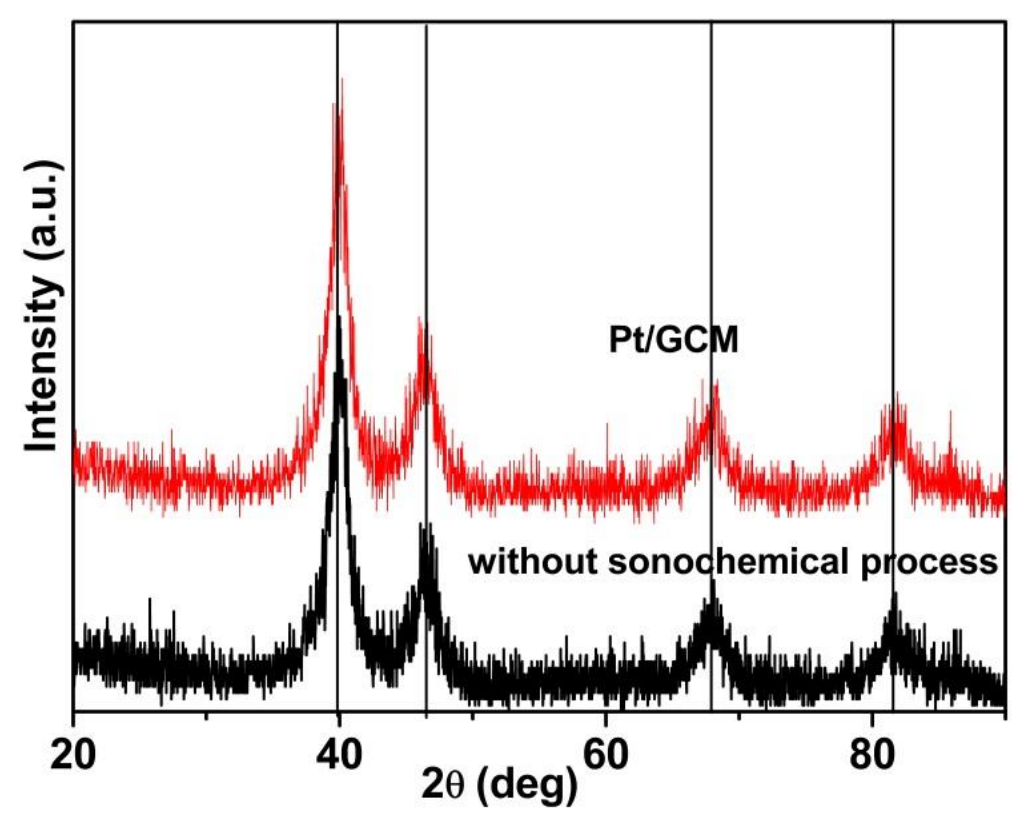

Figure S3. The XRS Patterns of Pt/GCM and Pt-Ni/GCM Prepared without Sonochemical Process. 

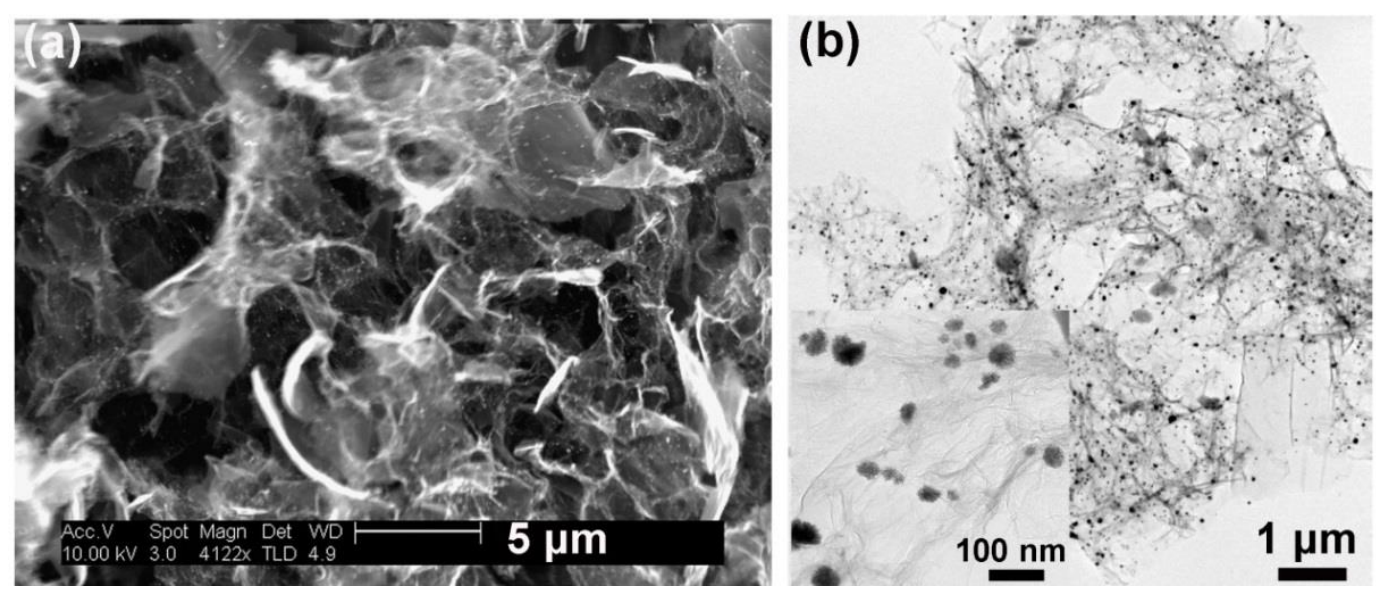

Figure S4. (a) The SEM and (b) TEM Images of Sample Prepared Directly by Gelatinization Process, and without Sonochemical Synthesis Process.

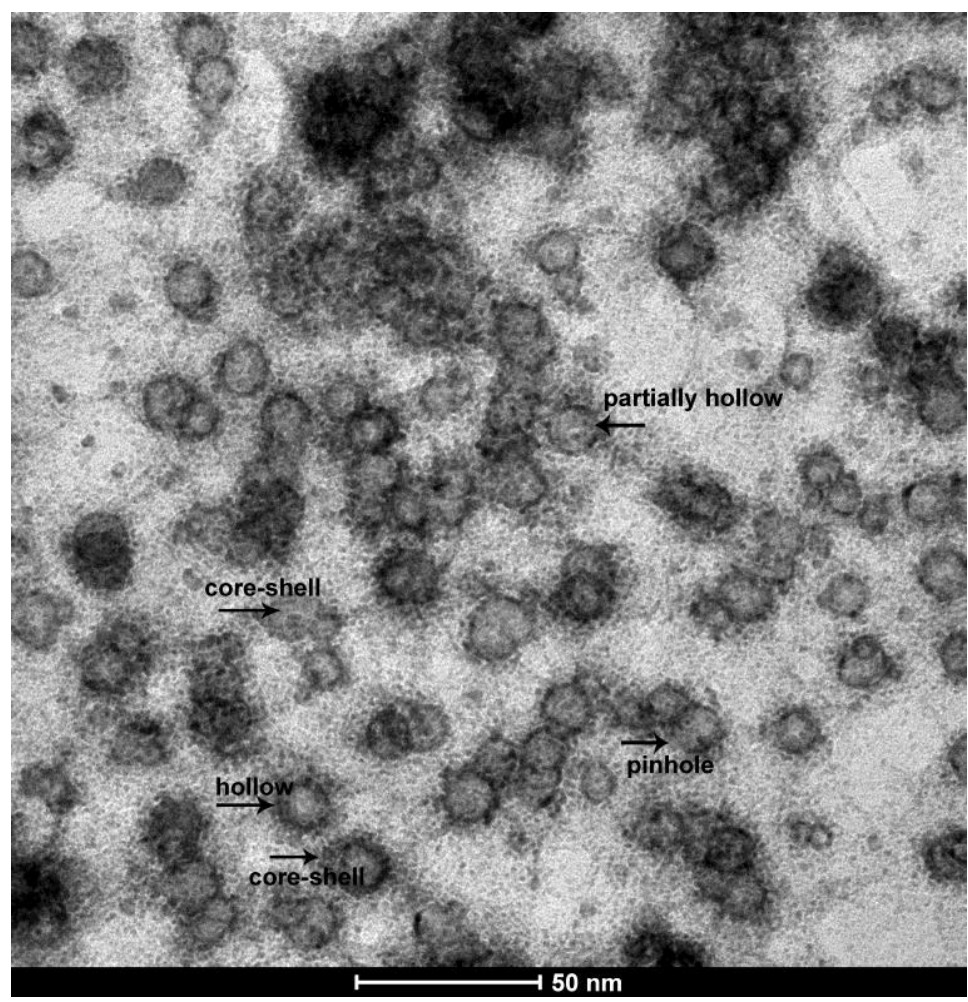

Figure S5. The TEM Image of Sample Prepared with the Sonochemical Synthesis Process. The Core-Shell Structure, Partially Hollow Structure, and Pinholes Can be Seen Clearly, which Proves that the Hollow Structure is Formed in this Section, and Galvanic Replacement is Indeed Happened. 


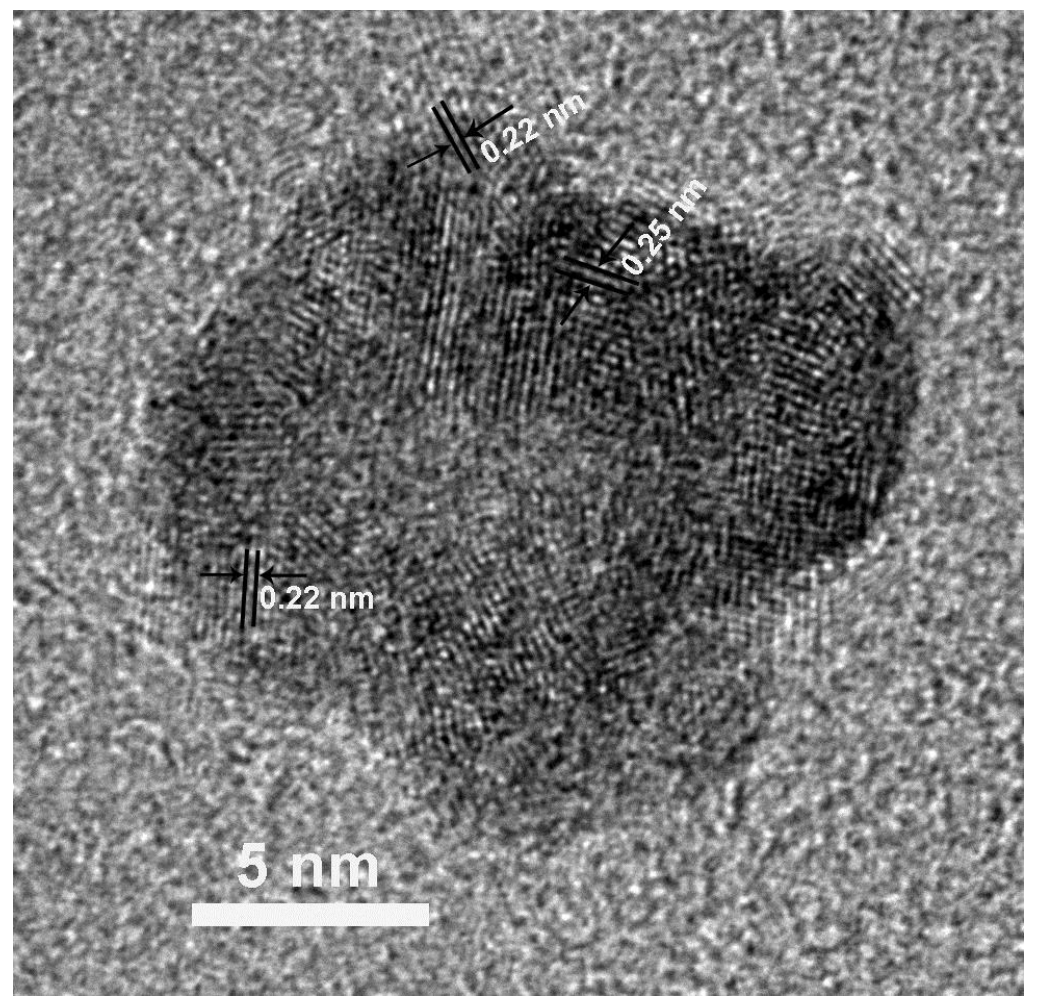

Figure S6. The HRTEM Image of Single Hollow Pt-Ni NP in Pt-Ni/GCM.
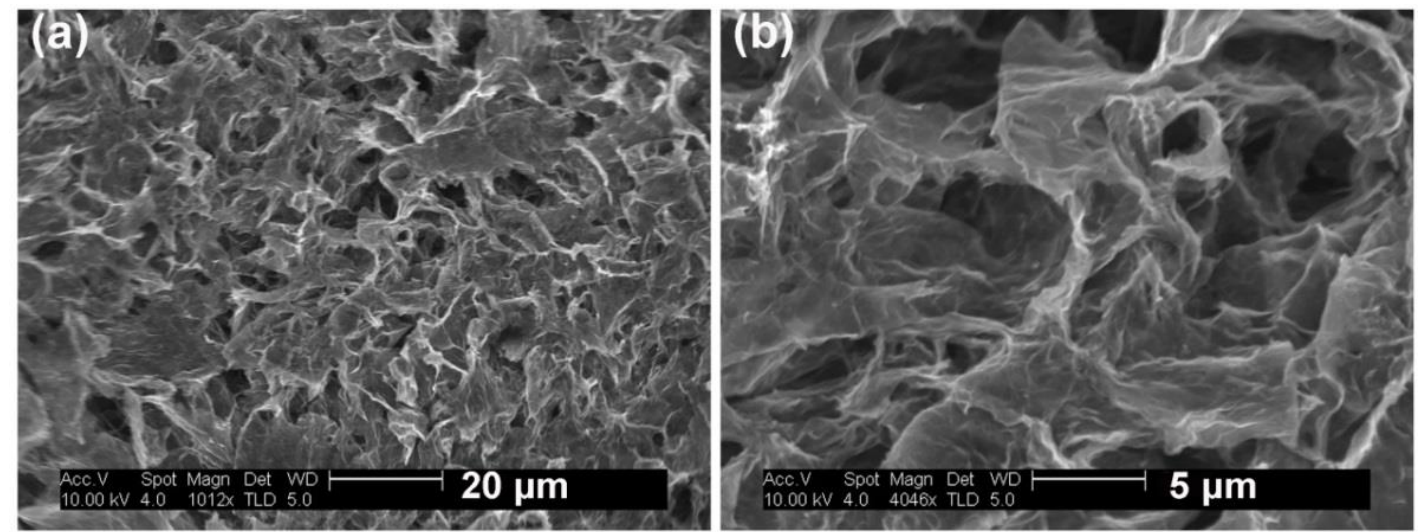

Figure S7. The SEM Images at (a) Low Magnification and (b) High Magnification of 3D Porous Graphene Monolith Prepared by the Same Method and Conditions without Deposition with Particles. 

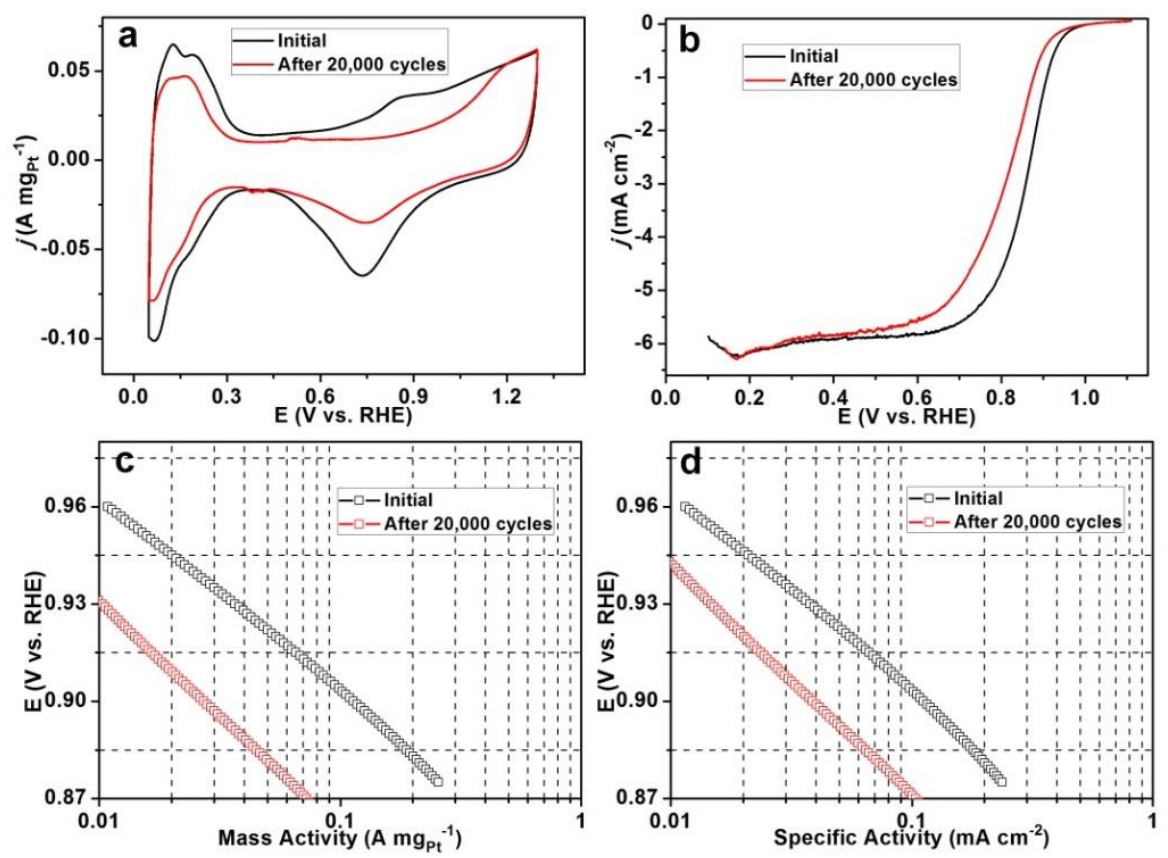

Figure S8. The Durability of the Commercial Pt/C Catalyst. (a) CVs, (b) ORR Polarization Curves, and (c), (d) the Corresponding Tafel Plots Before and After 20,000 Scan Cycles.

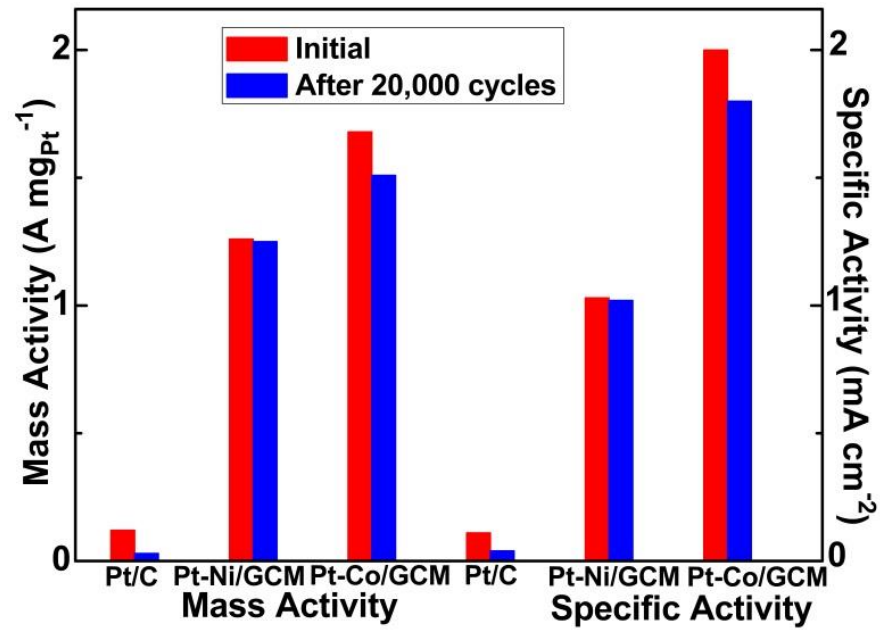

Figure S9. Mass Activities and Specific Activities of Commercial Pt/C, Pt-Ni/GCM and $\mathrm{Pt}-\mathrm{Co} / \mathrm{GCM}$ Catalysts before and after ADT at $0.9 \mathrm{~V}$. 

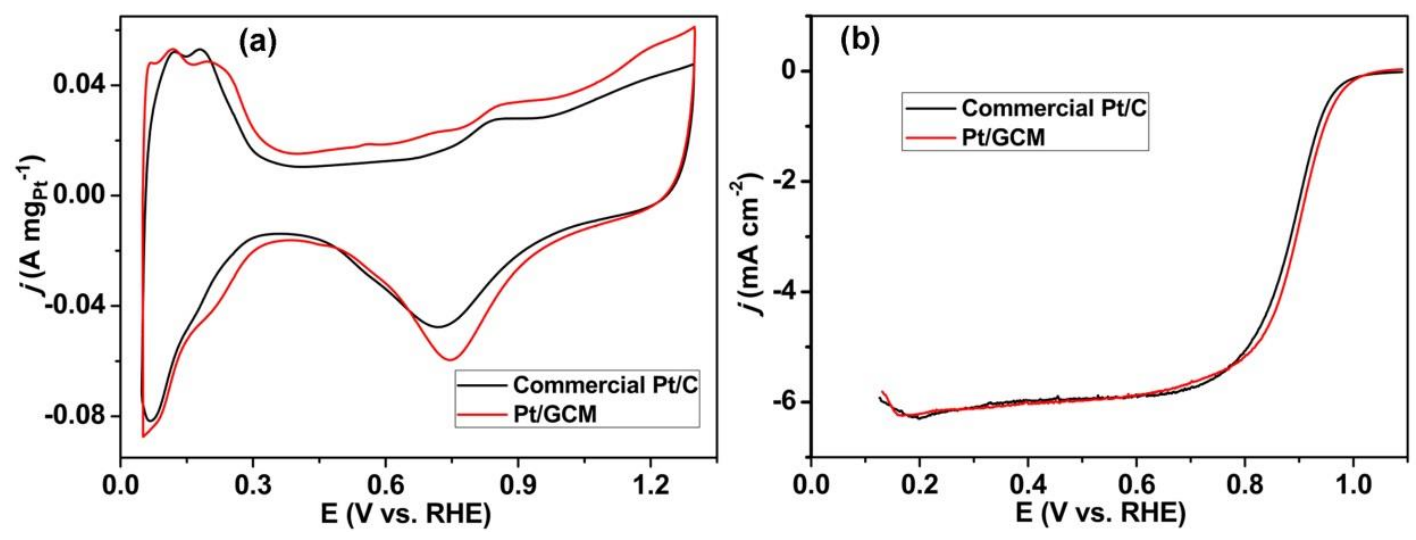

Figure S10. Electrochemical Properties of $\mathrm{Pt} / \mathrm{GCM}$ and the Commercial $\mathrm{Pt} / \mathrm{C}$ Catalysts. (a) CVs, (b) ORR Polarization Curves.

\section{Reference}

(1) Guo, S.; Zhang, S.; Su, D.; Sun, S. Seed-Mediated Synthesis of Core/Shell FePtM/FePt (M = Pd, Au) Nanowires and Their Electrocatalysis for Oxygen Reduction Reaction. J. Am. Chem. Soc. 2013, 135, 13879-13884.

(2) Strasser, P.; Koh, S.; Anniyev, T.; Greeley, J.; More, K.; Yu, C.; Liu, Z.; Kaya, S.; Nordlund, D.; Ogasawara, H.; Toney. M. F.; Nilsson, A. Seed-Mediated Synthesis of Core/Shell FePtM/FePt ( $\mathrm{M}=\mathrm{Pd}, \mathrm{Au})$ Nanowires and Their Electrocatalysis for Oxygen Reduction Reaction. Nat. Chem. 2010, 2, 454-460.

(3) Schmidt, T. J.; Gasteiger, H. A. Rotating Thin-Film Method for Supported Catalysts, Wiley, 2003; Chapter 22, pp 316.

(4) Gasteiger, H. A.; Gu, W.; Makharia, R.; Mathias, M. F.; Sompalli, B. Beginning-of-Life MEA Performance-Efficiency Loss Contributions, Wiley, Chichester, UK, 2003; Chapter 46, pp 593. 